\title{
Shape Grammar, Culture, and Generation of new vernacular houses (A practice on the villages adjacent to Rice fields of Mazandaran, in the north of Iran)
}

\author{
Majid Yousefniapasha, Catherine Teeling, John Rollo \& Dick Blunt
}

\begin{abstract}
This article is about an investigation exploring the vernacular environment of the villages adjacent to the rice fields of Mazandaran in order to identify the configuration and characteristic of its dwellings towards designing new vernacular dwellings. This is according to the combination of two models including 'shape grammars' and 'culture as model system'. In this regard, based on case study research, 4 villages and 44 houses within them have been investigated employing different methods including measurement, mapping, visual recording, one on one and focus group interviews. Houses have been analysed based on the framework that shape grammars provided towards identification of compositional rules. Some appropriate rules have been selected based on the achievements of the cultural study according to the culture as model system framework, and according to the climatic study that when applied generated new vernacular houses likely conforming to culture, vernacular architecture and new demands of local residents. This process has been successfully carried out for two real lands within two different villages. In this regard, two new vernacular houses have been created. The result shows that, the model contributed by this research can be efficient for generation of new vernacular houses within the region of this study.
\end{abstract}

Key words: shape grammars, culture as model system, vernacular architecture, rural architecture, Mazandaran

\section{Introduction}

Since the introduction of 'architecture without architect' by Rudofsky (1981), studying vernacular architecture has increasingly become one of the growing interests in order to obtain some knowledge enabling creation of new built environment. Learning from 'vernacular architecture' initiated from 'modernists', which was purely for architectural purposes supporting architects in designing new buildings (Oliver, 1997). Even if the lifestyle and culture are changing, and the changes are intensified by progress in science and technology, vernacular lifestyle and built environment have still useful lessons including 'aesthetical', climatic' or 'technological' lessons (Oliver, 1997; Rapoport, 1980; Rewal \& Jahanbegloo, 2010; Fathy, 1986; Webber and Yannas, 2014). Domestication of rice production in Mazandaran, a province located in the north of Iran encouraged local nomads living within the mountain area to becoming settlers in the two southern parts of the region; in the forest areas and in the adjacent flat plain area (Koulaeeyan, 2006). Domestication of rice production has formed a specific agrarian 
culture and settlement in Mazandaran a province located in north of Iran. The principles of this culture and lifestyle have affected the form of vernacular houses, configuration, and the structure of villages, and shaped a specific vernacular architecture within this region, which due to changes in local lifestyle from traditional way of living to modern lifestyle is being withdrawn. In terms of dwelling, local villagers want new vernacular house that respects their tradition and identity while accommodating the quality of life standards provided by modernity demonstrated in city areas. There is still no full model sorting these issues out.

The first application of shape grammars was used to analyse principles of existing architectural styles particularly vernacular architecture during the first two decades of its creation. Studies have been undertaken for vernacular architecture including; Ice-ray: a note on the generation of Chinese lattice designs (Stiny 1977), the Taiwanese traditional house (Chiou, Krishnamurti, 1996), Queen Anne houses (Flemming, 1987), Ndebele homesteads (Herberts, Sanders, Mills, 1994), and the Islamic gireh, Korean pattern (Lee, Park, Lim, Kim, 2013). The formalism of the shape grammar process is one of the most convincing methods available to show our understanding of the composition of existing designs (Koning and Eizenberg, 1981). Accordingly, the methodology developed by Shape Grammars is supportive for analysis of existing vernacular houses of this region, which has not been undertaken so far. The second application of shape grammar relates to the possible use of shape grammars to enable architects and designers to create new designs with embedded design criteria (Stiny and Gips, 1972). In this regard, researches such as the Palladian grammars carried out by Stiny and Mitchell (1978), and most notably the research on Frank Lloyd Wright's prairie houses (Koning, Eizenberg, 1981) have contributed new alternative designs based on application of the identified rules, a model supportive for this research.

Within the 'Shape Grammars' the cultural or human behavioural and climatic characteristics of a place, its dwellings and their development over time has not been considered. In term of culture, the only created model named 'Culture as model system', proposed by Rapoport (2006b) is useful in understanding characteristics of 'systems of activities', cultural components, local preferences, demands, and provides a framework for conduction rules evaluation. While because of lack of consideration of this model to physical manifestations of cultural actions and activities including shape, geometry, climate, material and construction technology, it has not been translated to a full methodology to be employed for designing new alternatives within vernacular environments. Therefore, a combination of both of these theories enabled this research generation of new rural houses to be culturally and climatically admitted. In this regard, evaluation of identified rules according to the cultural and climatic influential factors within the region leads to setting up compositional rules, that when applied, can generate sustainable and culturally appropriate new houses. The process of this model application and its results are explained through this paper. 


\section{Methodology}

This research is founded on case study research. Accordingly, four villages totally have been selected between 1159 villages located within the forest area and in the forest border adjacent to flat plain area of two major cities' counties ${ }^{1}$ called Sari and Babol. The first rice cultivation and domestication dating back 100 B.C started from these counties (Koulaeeyan, 2006). They contain the most villages and the most populated rural areas (Statistical centre of Iran, 2015). These four villages have been selected, based on predefined criteria including; containing 200-2000 population that this size is able to make a good neighbourhood (Alexander, 1977; Moughtin and Shirely, 2005), being at least 15 kilometres far from the major city of the county, existing of traditional lifestyle, houses, and materials, containing rice fields. Accordingly, the selected villages are much historically old; are with less change in their rural characteristics and the principles of traditional lifestyle and traditional space configuration of villages and houses are still dominantly exist supporting obtaining sufficient information about compositional implications within traditional architecture.

44 houses within these villages from different identified styles have been selected as samples. These were measured, mapped by CAD software, and visually recorded and have been analysed within the framework that shape grammar provids (Stiny, 1972). Identified rules have been selected through evaluative process according to the Rapoport's model including cultural implications and according to the climatic issues, which led to definition of set of rules for designing new vernacular houses.

\section{General characteristics of vernacular houses toward introducing the typology}

Dwellings of the region are in form of residential complex called 'sere' which includes enclosed settings (buildings) and various open settings (fig 1). These buildings are all located in a private land, which is called 'property' in this paper. Dwellings are designated to accommodate life activities along with accommodation of production activities particularly associated with food production. All of these activities are located in either enclosed or open settings. Indeed, they are 'systems of settings', which are closed or open where 'systems of activities' related to life or food production take place (Rapoport, 2006a, p.20) within the property (sere) and inside the buildings. The main settings, which are enclosed structures as outbuildings located within a property, are the house building, livestock and poultry houses, and outside toilet. Front yard, backyard and garden are three main open settings of a property. All enclosed settings are distributed across the organic and non-geometrical land according to the location of the living house and entrance and the direction of north ${ }^{2}$. The focus of this paper is just

1 : 'City County' in this paper means a city with different rural districts located around including different villages within these rural districts. Usually each city county includes flat plain, Forest and mountain areas.

2: In this paper, north direction represents north zone direction. North zone direction is an angle from north-east to north-west which have approximately the same condition within the region. It is also the same for south zone direction. 
on identification of rules to design the house building. Rules for designing the property is not the concern of this paper.

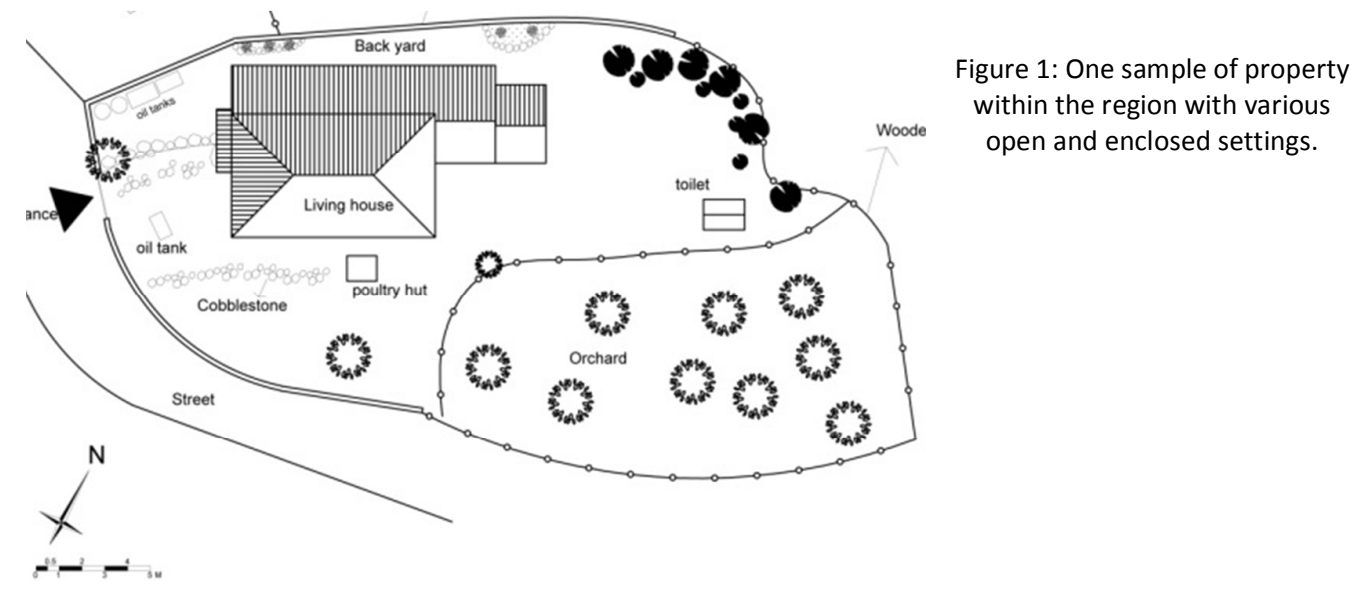

Rural houses within the region are based on a long tradition of applied rules and regulations linked to residents' way of life. Before definition of set of these rules, this research conducted the typology of existing houses. Four types, mainly representing different vernacular houses have been identified. This typology has been founded on the criteria and typology that local residents have introduced, which is based on the whole shape of enclosed spaces of the house. Accessories such as baths, toilets, and kitchens have been added to the primary shape of the house after occupation, which have not been considered within this typology as well as semi-enclosed spaces, which are usually located in front of the house. These types are 'row house', which is linear in enclosed shape, 'saddle house', which its enclosed space is U shape, 'semi-saddle or Vaziri house', which is L form in shape of enclosed spaces, and 'composite houses', which is a combination of at least two other types. Variations of these types are based on the number of rooms, and number of storeys. One sample of these four types is represented within table 1.This typology is the base data bank for identification of compositional rules of the vernacular houses.

\section{Compositional rules to design rural dwellings}

Accordingly, a parametric shape grammar is developed based on actual design and construction processes according to professional masters' opinions and villagers' views derived from the conduction of several one on one and focus group interviews. In addition, grammatical rules of new styles of houses have been introduced in order to find out the changes within configuration of houses in order to conduct a comparison analysis towards verification of better rules appropriate for new life style of villagers. Identification of grammatical rules is illustrated based on four vernacular types of dwellings. Rules have not been introduced for each type of house individually; they are constantly redefined and so are able to relate to all four types. Regarding the typology of houses, Half-saddle type is an evolution of the Row type and Saddle type is an evolution 
of Half-Saddle type, and the composite type is an evolved version of all or combination of them. Therefore, these types have considerable common characteristics so that-many rules are common within all types, this being the case; they have been set up through one common package. In this hierarchical process, specific rules have been added in order to enable the grammar to define and generate different types. In this regard, 138 compositional rules for creation of house buildings in $2 \mathrm{~d}$ and $3 \mathrm{~d}$ have been identified, which have been illustrated within supplementary document. The process of rule definition is divided into two distinctive phases following to the actual house design process. The master at the first phase determines the rules that influence the configuration of dwelling design in property scale, including definition of the approximate territory and location of construction such as the house as the main building, the location of other outbuildings and open areas. Design in this scale is not the concern of this paper. The second phase, which is the topic of this article, articulates the set of rules that embody the design and construction of different types of the building of houses and regulate the organisation of 'systems of settings' involved in forming the configuration of houses. Identified rules conveying the characteristics of 'systems of settings' are evaluated in order to achieve their efficiency for locals' lifestyle according to the cultural, social, and climatic criteria (Kasmaei, 2010; Rubel and Kottek, 2010), which in consequence of this evaluation, appropriate rules to design and construct of new houses is achievable.

In order to test the validity of these rules in terms of creation of new appropriate vernacular house, two real land plots within two case study villages have been selected. One of them is located in a village commonly with sloped land within the forest area. The other one is located within the forest border common with flat land (fig 2). Two sets of appropriate rules have been selected according to the shape and conditions of the plot lands forming appropriate house in 2D and 3D. The house design begins with definition of the living room as the main enclosed space of the rural house. The first step is to determine a point on the land within the construction area as a benchmark for construction of the house, which must be selected very carefully. Traditionally, it is better to be located on the back edge or corner of the house; otherwise, the living room extension could not be possible. This is fulfilled by application of rule 1 (fig 3,4). After the definition of the base point is confirmed, the owners sacrifice a sheep, cow or poultry to celebrate the construction of a new house with all workers including family members, friends and relatives involved in construction of the house. They all hope and wish good fortune for the owner, his family and the house.

The next step is to define the best orientation according to the north and wind directions, proper proportions, shape, orientation, size and location for the living room, which is the main determinant space and is where most of their indoor residential activities take place. Through analysis of the site and application of rules 2,3,4,5 and 6, the north direction and proper wind directions are determined. After that, the proper size and proportions are defined by application of rule 6" and 12 considering most 
Table 1: Table shows four different types of vernacular house within the region

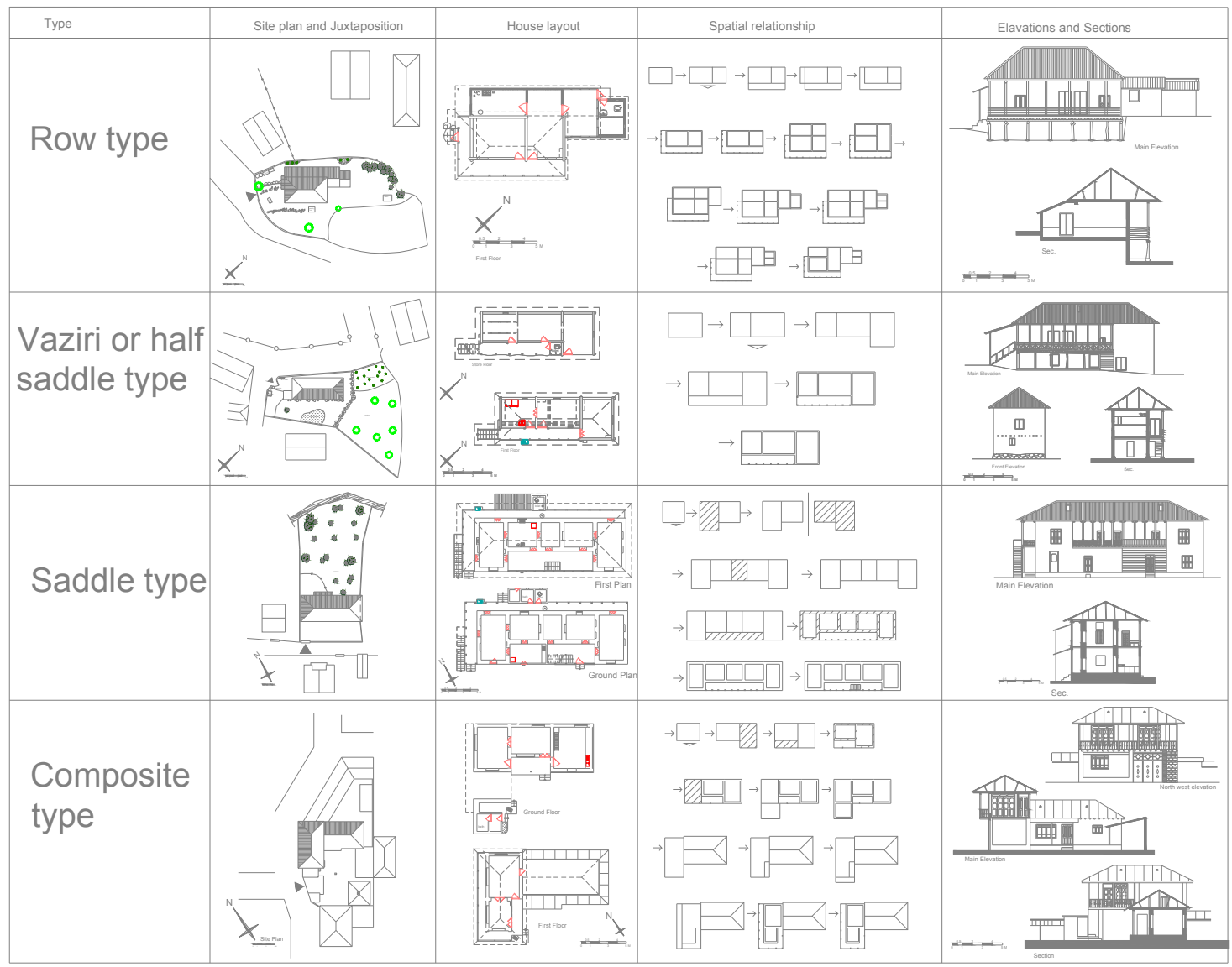

acceptable proportions within vernacular houses of the region. Rules 6", in addition, defines the preferred shape for the desired living room, which in the region is predominantly rectangular. The sizes of living rooms for new vernacular houses should be bigger than vernacular samples due to new activities and villagers' new lifestyle. This proportion and size in result of application of rule 12 determines the appropriate sizes of most other rooms. The best orientation of the living room and the orientation of the house are defined by application of rule 8'. The best orientation within the region is facing to south, enabling the room and the house absorbing much sunshine and capturing proper wind for cross-ventilation in order provide desired comfort. Figure 3 represents the appropriate size, shape and orientation of the living room in the village of flat land and figure 4 shows the same purpose for the house in the village of a the forest area. The design of the living room must be transferred into the real land plot design in order to endorse the rest of the design stages. This is essential in order to find out if the house could be fitted within the pre-designated area. Figure 5 shows the location of the living room within the two land areas. If designed living rooms and its location and orientation are not efficiently desired, the design process must be revised and repeated. 
Figure 2: Two selected real lands for designing new rural house. The upper one belongs to a village in the forest border area with flat plain ground and the lower one is located within the forest area with slope ground.

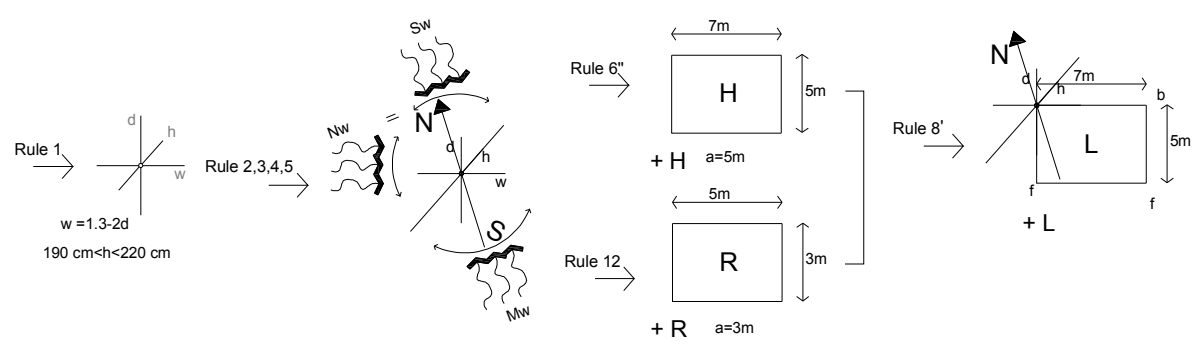

Figure 3: Definition of proper shape, size, and orientation for living room of the new house in Diva.

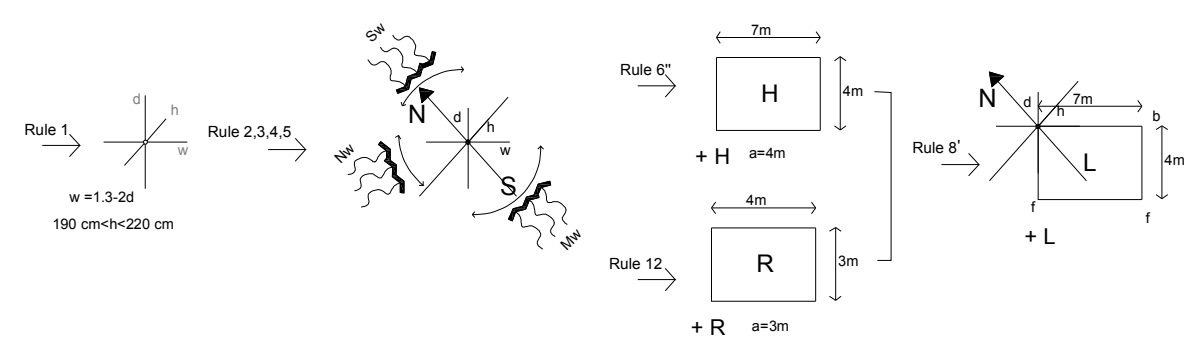

Figure 4: Definition of proper shape, size, and orientation for the living room of the new house in Perija

In order to carry on the process of the design, firstly the type of the house must be agreed with the owner. In respect to the findings from interviews, questionnaires, cultural and climatic studies, and analysis of vernacular houses within different areas of the region, appropriate types for new houses within two villages can been identified. Accordingly, local residences in the village of the flat land prefer to have a two-storey house with two bedrooms. This two-storey house should have a front porch, kitchen and living room on the ground floor with a toilet and bath connected to it while two bedrooms are arranged upstairs on the first storey and with a front porch. Residences in 

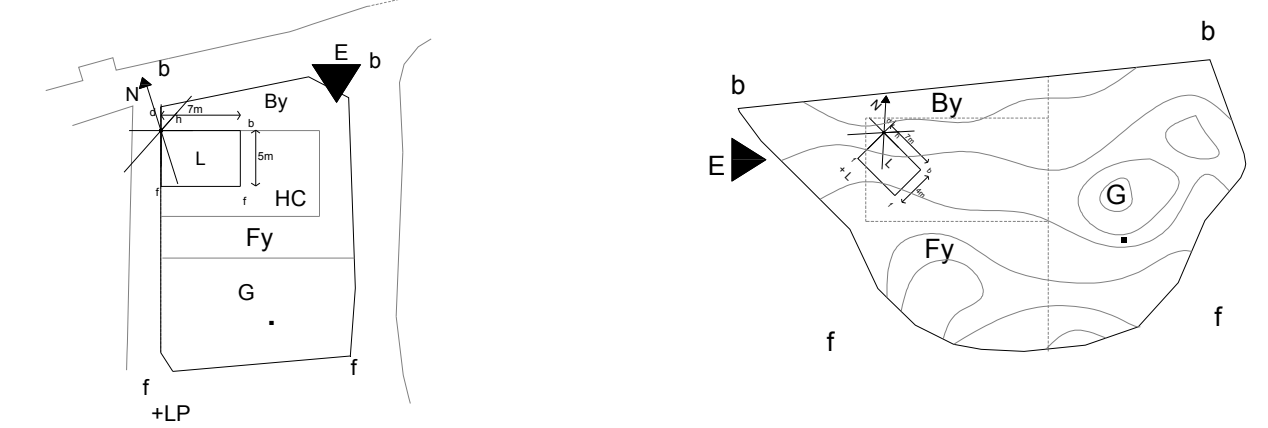

Figure 5: Location of designed living rooms within two real lands. Left one represents the case in flat land and right side figure represents the case on slope land in the forest.

the forest area interest to design a one-storey house having two bedrooms. In this house, toilet and bath should be located between these bedrooms, living room is better to be open plan with the kitchen and a front porch should be located in front of the house.

According to the identified appropriate types for the two cases, the rest of the new house design process resumes. At this stage other required spaces and desired components of the house such as the kitchen, bedrooms, toilet, bath, staircase, front porch, doors and windows are designed and added to the living room according to the owner's desire and related type. Two dimensional design is the outcome of this stage. Figure 6 exhibits selected rules and explains the reason of their selection and the process of application of them for designing the house on flat land in two dimensions, and this process for the house on the slope roof is shown in figure 7 . The termination of the process of house design in two dimensions means the start of the process of 3D design; this is exhibited within figures 8 and 9 including the selected rules, the reason and their application process. The process of designing the house terminates once design in 3D is fulfilled, which ends up by instalment of the slope roof.

After the wooden structure of the sloped roof is erected on a vernacular house and by application of rules 74-95, the owner of the house usually arranges party inviting masters, labourers, neighbours, family and relatives at the site of house construction. Wife of the owner man prepares some traditional sweets, fruit and drinks to entertain-the guests. This tradition is being forgotten from the system of new house construction because of the elimination of sloped roof from volume configuration, which is in addition to disappearing of wood as the main material of construction. In addition to this party and after moving into the new house, the owner arranges another dinner party inviting relatives and best friends. Invited guests usually present the owner with a precious gift in return. This party is still common within the society of the region. These parties perform social role enforcing emotional ties between different members of the 

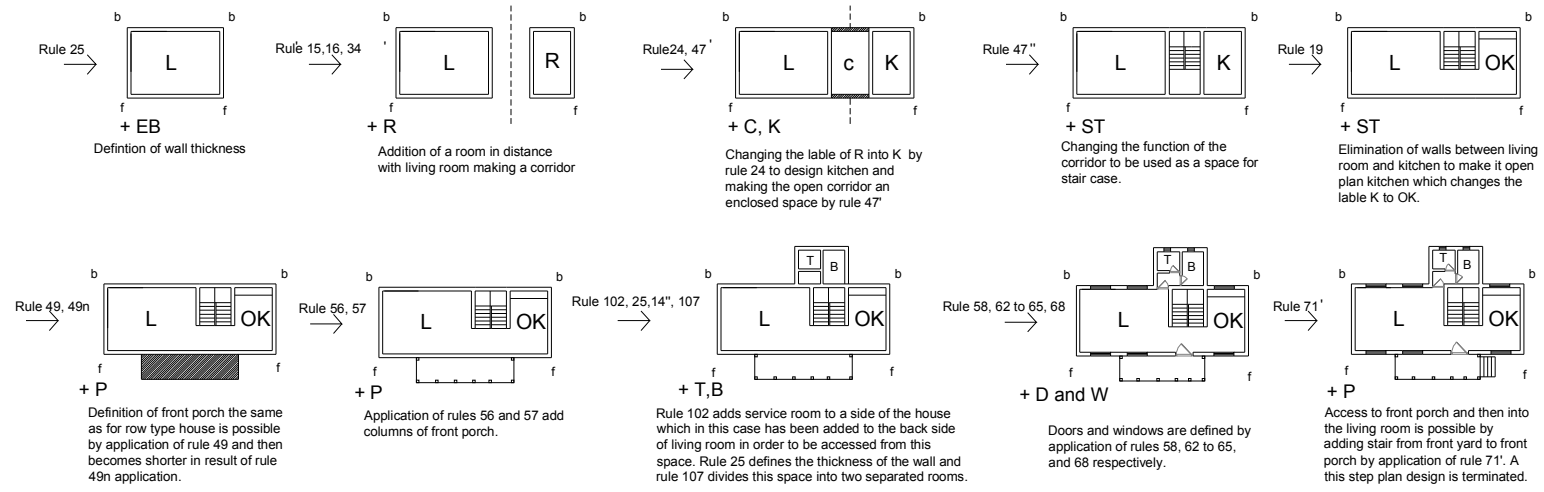

Figure 6: The process of applications of rules in order to design the new house in flat land in 2D.
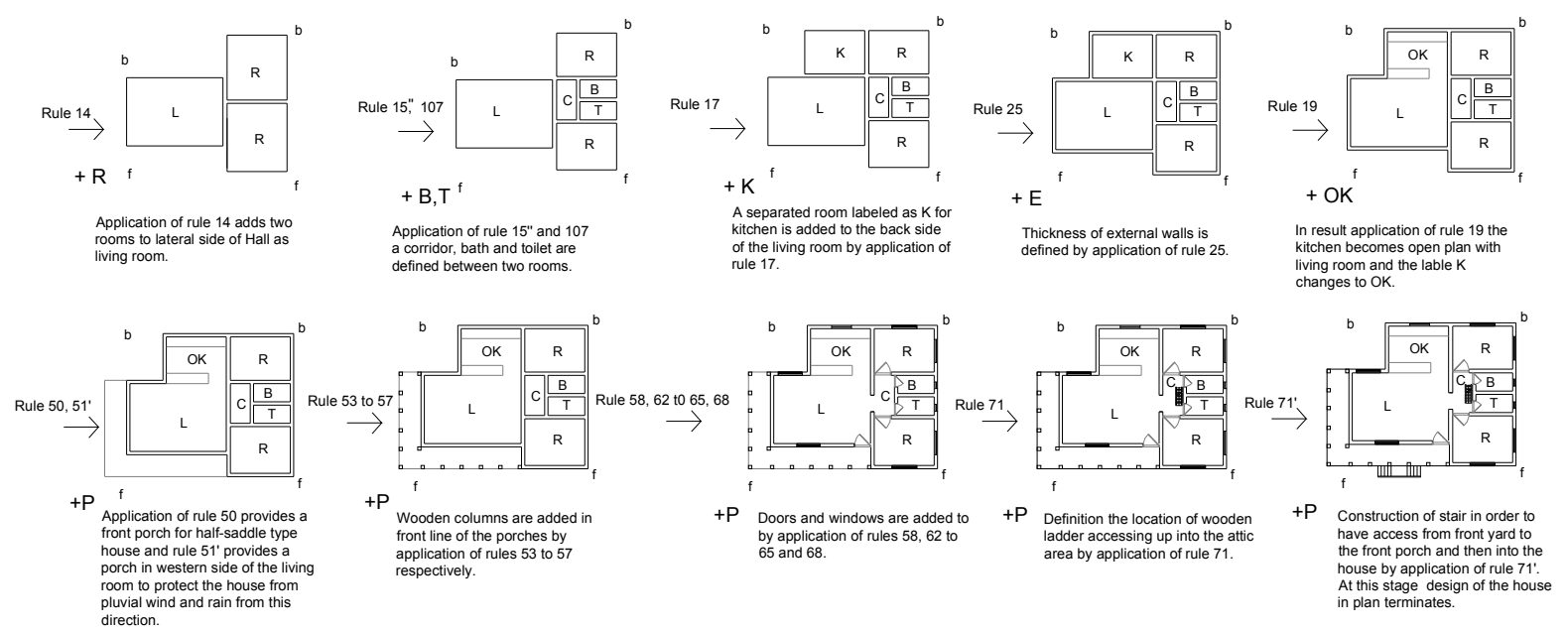

Figure 7: The process of applications of rules in order to design the new house in sloped land in 2D.

society specially a family or a small community promoting sustainability in terms of social aspect.

It is necessary to mention that in order to completely design the new house, extra rules are required. Those rules are generally related to designing details such as decorative or ornamental components of a house including design of doors, windows, parapets, and capital of columns, which in this study have not been considered and performed. These details added to the outcomes of this research were inspired by existing local samples within the region. New house designed in the village located in flat plain area is shown in figures 10 representing property scale and 11 representing house scale, and the new house for the forest area with slope ground is presented through figures 12 for property scale and 13 for house scale. 

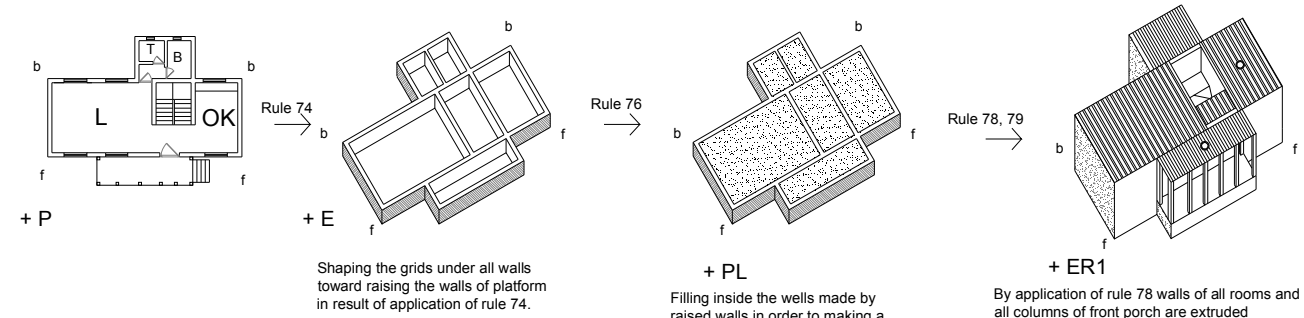

$+\mathrm{PL}$

$$
+ \text { ER1 }
$$

Filling inside the wells made by raised walls in order to making a
flat platform by application of rule

By application of rule 78 walls of all rooms and all columns of front porch are extruded
according to predefined size for height of room After that by application of rule 79 all rooms except the stair case are cove
since this is teo-story house.
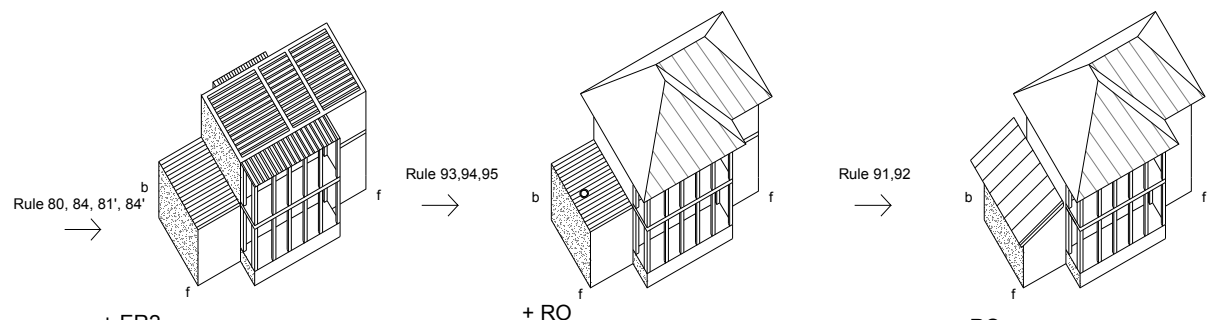

$+\mathrm{RO}$

Application of rule 80 and 84 extrudes all rooms that have double height in two-story houses and they are in the same size rules 81 ' and 84 ' half or just every part of lower room can be extrude in second floor which in this case have been applied on application of rules 93,94 , and 95 respectively

In this kind of designed houses, the roof of one height making one sided slope roof which terminates designing living room making smaller room upstais.

Figure 8: The process of application of rules in order to design the house of flat land in 3D, which is two-storeys high.
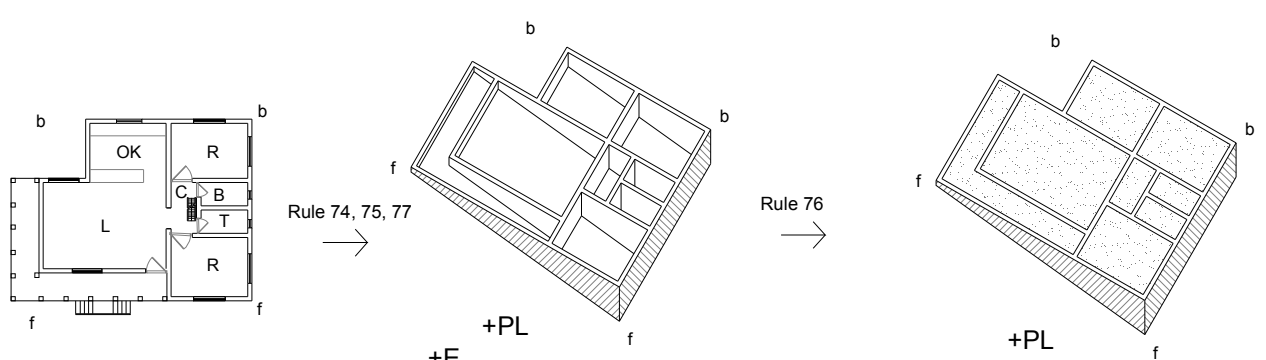

$+\mathrm{E}$

Shaping the grids under all walls toward raising the walls of platform. The land of this case is sloped so that the process of construction of raised platform is possible in result of application of rule 74,75 , and according to the direction of the slope in this caase by application of rule 77 .

Filling inside the wells made by raised walls in order to making a flat platform by application of rule 76 .

Figure 9: The process of application of rules designing the house of sloped land in 3D, which is one storey high.

\section{Discussion}


These new designed houses resemble vernacular samples in appearance while they take advantage from new spatial configuration and space organisation inspired by vernacular types. They have been inspired by climatic and sustainable rules that were employed within vernacular houses. Accordingly, both of these two new designed houses climatically take advantage of orientating towards the south (zone) adsorbing appropriate sunshine, having external hip sloped roof projected from four sides in order

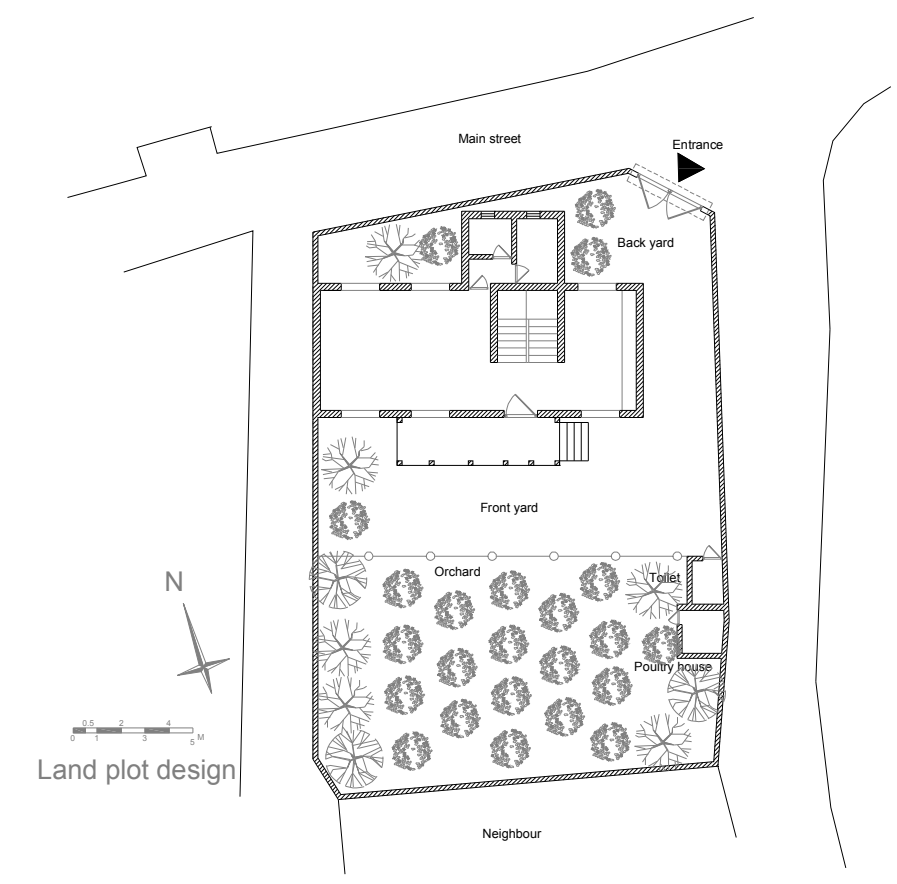

Figure 10: land plot design of the new house in flat land defining the location of the house, outbuildings, entrance into the land, and location of open spaces.

to protect the volume of the houses from rain and making shade protecting it from hot sunshine of summer, and a flat inside ceiling making an attic area in between. Conduction of necessary cross-ventilation is feasible by having two windows including one in the south and one in the north within main settings such as living room, which is the main space. In addition, both houses are elongated east west, which climatically allows obtaining more sunshine and capturing winds from different directions in order to provide thermal comfort (Kasmaei, 2010; Thabaz \& Jalilian, 2009). The proposed house in flat plain area, particularly because of these two reasons has been designed in two storeys, which was common form of vernacular house in this village According to the two generated houses, the living room is the heart of the house connecting all rooms where most occupants' systems of activities such as sitting, eating and drinking together, entertaining guests and watching TV take place. This room has the same proportion as vernacular living rooms but is larger. This is because of new demands, new furniture, sitting styles changed from sitting on the floor to sitting on the sofa, and locals need large spaces to entertain guests. The kitchen is a new important setting for local population, which can be open plan with a living room or independent but 

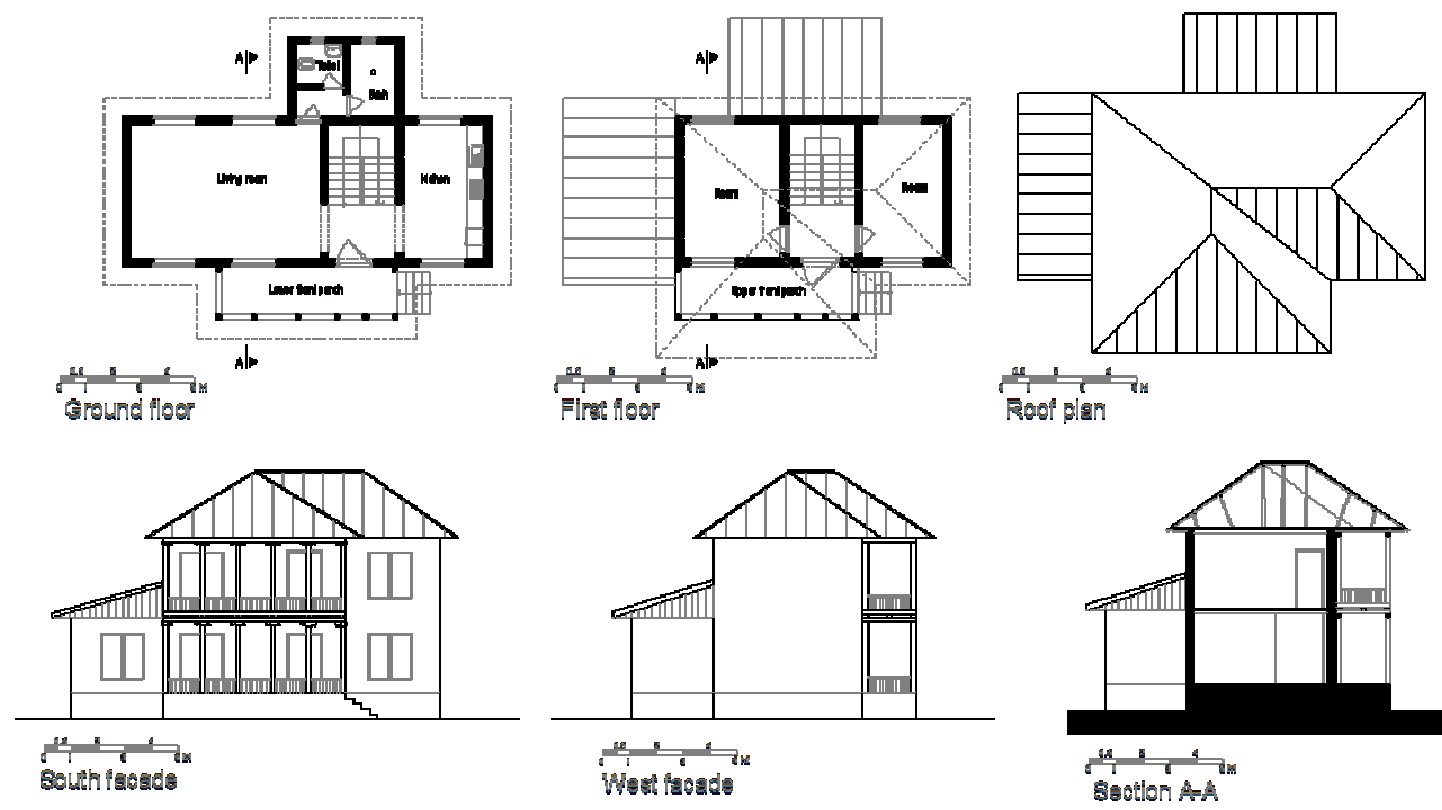

Figure 11: Plans, elevations and section of designed new house in flat land.

connected to this room by a door. The size and proportion of the kitchen is proposed to be suitable for new defined function accommodating new kitchen appliances imported to these villages such as a fridge, oven, washing machine, sink, cabinet for food and dish storage, and supporting different activities such as cooking, eating, drinking and sitting together. As the kitchen does not need to get sunshine from the south, it can be located at the back of the house getting sunshine from the east, and by being open plan with living room; it can take advantage of cross-ventilation by application of window on its wall. The front porch is another most important setting within vernacular houses of this region and in Iran (Foruzanmehr, 2015), which shapes the configuration of new houses and climatically has important role in achieving thermal comfort. It is located in front of the proposed houses and performs as the entrance connecting the inside of the house to the outside and the front yard. The size of this space in longwise has become shorter to reduce the expenditure of house construction while the size of the deep is wider than vernacular style in order to make this space appropriate for new lifestyle. Additional

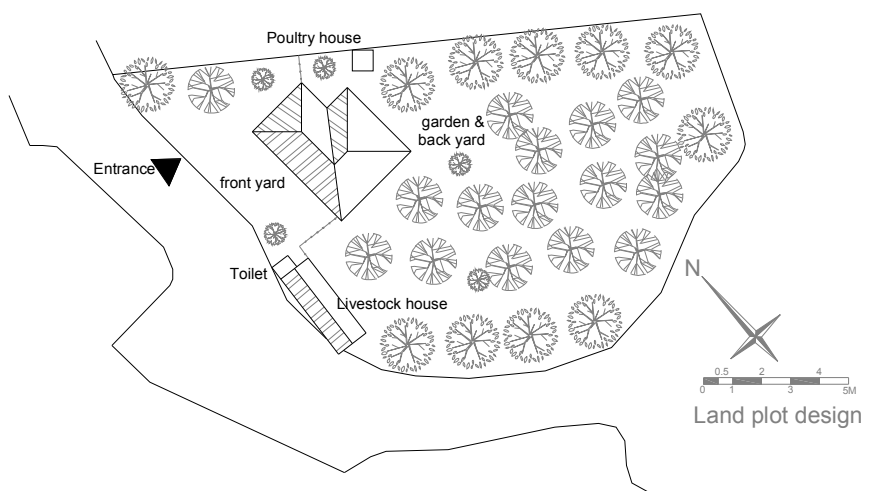

Figure 12: Land plot design on a sloped land of the new house in sloped land defining the location of the house, outbuildings, entrance into the land, and location of open spaces. 

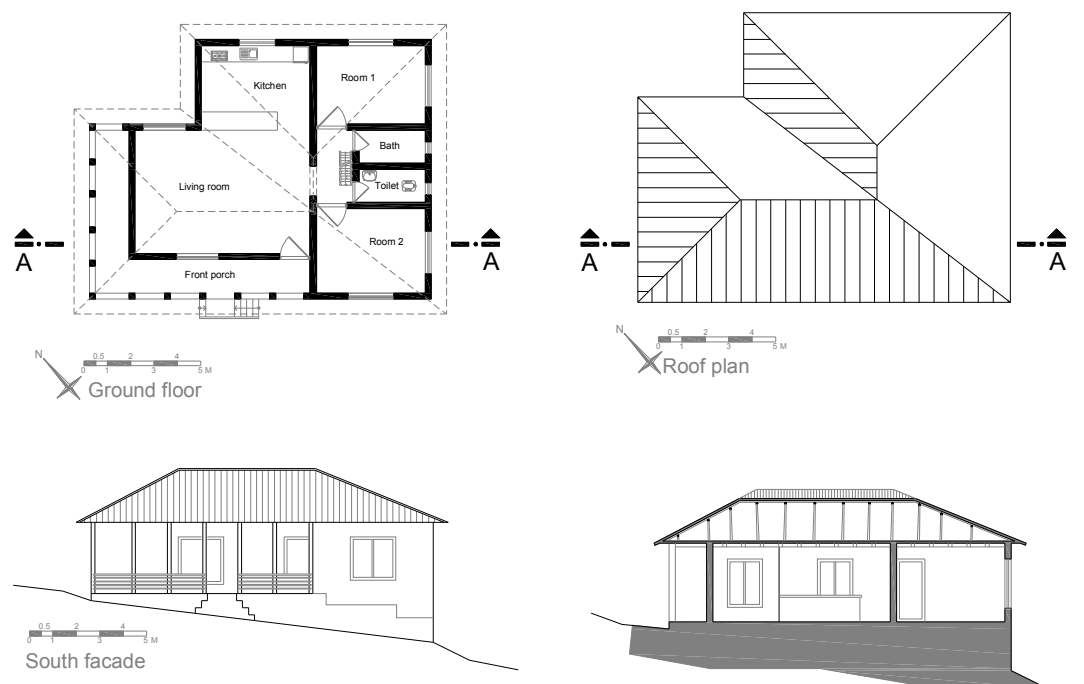

South facade

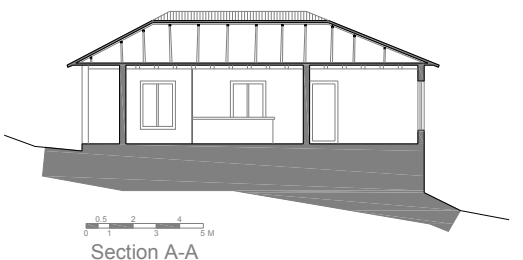

Figure 13: Plans, elevation and section of designed new house in sloped land.

rooms can be set up within the house configuration serving as a private room for all members of the family; their size and proportion are the same as vernacular samples but are solely accessed from the living room. Besides that, the bath and the toilet depending on the owner's desire can be set up inside or outside of the house. In these houses, they are accessed indirectly from the living room, which is much convenient and acceptable for local villagers.

According to the new designed houses, first, the compositional rules embody the characteristics and spatial configuration of existing vernacular architecture of Mazandaran province. Second, these set of rules incorporate important criteria that relate to cultural, physical and climatic conditions of the region. Third, the application of these rules have capacity to generate new architectural forms for the future that respond to existing vernacular paradigm and new ways of living to sustain culture and identity in contemporary development. Thus, can be said that the shape rules collectively represent the style of vernacular houses in Mazandaran. In addition to those criteria, these collective rules have been identified and evaluated based on climatic and cultural constraints, which have been proposed and successfully undertaken 'altogether' within this research for the first time in shape grammar literature. In this respect, it is expected that the new designed plans of houses respond to cultural characteristics and current systems of locals' activities at home, supporting new lifestyles and demands while it is sustainable responding to the specific climatic conditions of the region.

\section{Conclusion}

This study has set out to propose a process for designing new vernacular houses based on cultural traditions and sustainability of the villages located besides the rice 
fields of Mazandaran in the north of Iran. In this regard and fallowed by case study research and topology study, four different identified types of vernacular houses have been analysed within the framework that shape grammar provided (Stiny, 1972); the result was definition of set of rules employed for house design and construction. Identified rules have been evaluated according to the achievements of cultural model proposed by Rapoport and climatic studies. This evaluation led to identification and setting up compositional rules, that when applied, generated sustainable and culturally appropriate new houses for the villagers of the region of this study. Two samples of application of those rules have been introduced representing two types of new houses for two villages. These samples (1) clarify the underlying commonalities of the structure and appearance, (2) supply the conventions and criteria necessary to determine an instance of the style, and (3) provide the compositional machinery needed to design new buildings that are instances of style (Stiny and Mitchell, 1978). Additionally, these new houses are sustainable and climatically appropriate as the grammatical rules employed for their creation, are derived from conduction of evaluation based on cultural study, and climatic conditions of the region. It has been experienced through this research that Shape Grammars' is one of the most convincing theories, method available to represent and understand the composition of designs. It can represent physical characteristics of architectural spaces. It also has been fulfilled that through the identification and selection of specific rules and shapes, they can be utilised to generate new designs in both 2 and 3 dimensions for this region as it has been undertaken for other cases (Koning and Eizenberg, 1981; Flemming, 1987).

In consequence of this experience, a method has been developed that suggests identification and selection of appropriate rules for designing new alternative rural houses through an evaluation process in consideration to the findings of climatic and cultural investigations. Accordingly, shape, form, and geometry are as important as cultural variables, human behavioural and climatic characteristics when designing a new house within a vernacular environment aiming to be acceptable by local residents. This model which has been proposed in this research entitled as 'Shape and Culture' is a combination of two models including 'Shape Grammars' and 'Culture as Model System', which expands both of them and seems can be equitably employed in other vernacular environments of all around the world.

\section{Bibliography}

Alexander, C. (1977). A pattern language: towns, buildings, construction. New York, USA: Cambridge university press.

Chiou, S-C. ans Krishnamorti, R. (1996). African shape grammar: a language of linear Ndebele homesteads. Environmental and planning B: Planning and Design, 21, 177-190.

Fathy, H. (1986). Natural energy and vernacular architecture. (W. a. Shearer, Ed.) USA: Chicago press. 
Flemming, U. (1987). More than the sum of pars: the grammar of Queen Anne houses. Environment and Planning B, 14, 323-350.

Foruzanmehr, A. (2015). People's perception of the loggia: A vernacular passive cooling system in Iranian architecture. Sustainable cities and society(19 (2015)), 61-67.

Herbert, T., Sanders, I and Mills, G. (1994). African shape grammar: a language of linear Ndebele homesteads. Environment and Planning B(21), 453-476.

Iran, s. c. (n.d.). Retrieved 2016, from www.amar.org.ir.

Kasmaei, M. (2010). Climatic design, Zoning and guidlines for moderate climates (Guilan and Mazandaran provinces). Teharan, Iran: Building and housing research centre.

Koning, H. \& eizenberg, J. (1981). The language of the prairie: frank Lioyd Wright's prairie houses. Environment and planning B(8), 295-323.

Koulaeeyan, A. (2006). Sari and the beginning time of rice civilization. Sari, Iran: Shelfin Publication.

Lee, J-H., Park, H-J, Lim, S and Kim, S-J. (2013). A formal approach to the study of the evoloution and commonality of patterns. Environmental and planning B: Planning and Design, 40, 23-42.

Moughtin, C. and Shirley, P. (2005). Urban design: Green Dimension. oxford, UK: Oxford press.

Oliver, P. (1997). Ensyclipedia of vernacular architecture of the world (Vol. 1). UK: Cambridge university.

Rapoport, A. (1980). Thirty three papers in environment-behaviour research, human behaviour and environment. Newcastle, UK.

Rapoport, A. (2006a). Culture, Architecture and design. Chicago, USA: Locke science publishing company.

Rapoport, A. (2006b). culture as model system. In L. \&. A. Squith, Vernacular architecture in the twenty-first century, theory, education and practice (pp. 179-200). London, UK: Taylor and Francis.

Rubel, F., and M. Kottek. (2010). Observed and projected climate shifts 1901-2100 depicted by world maps of the Köppen-Geiger climate classification. Meteorol. Z., (19), 135-141.

Rehwal, R. \& Jahanbegloo, R. (2010). talking architecture. New Delhi, India: Oxford university press.

Stiny, G. (1977). Ice-ray: a note on the generation of Chinese Lattice designs. Environment and planning B, 4, 89-98. 
Stiny, G. and Gips, J. (1972). Shape Grammars and the Generative Specification of Painting and Sculpture. (I. C. Freiman, Ed.) Information processing 71, 1460-1465.

Stiny, G. and Mitchell, W.J. (1978). The palladian grammar. Environment and Planning B, 5, 5-18.

Thabaz, M. \& Jalilian, S. (2009). Designing principles according to different climates in Iran. Shahid Beheshti University.Tehran. Iran. P.32

Weber, W. and Yannas, S. (2014). Introduction. In W. a. Weber, Lessons from vernacular architecture. London, UK: Routledge, pp. 1-7. 


\section{Page 17 of 26}

\section{Identified rules that local people used to employ in order to design and construct the}

vernacular dwellings in 2D.

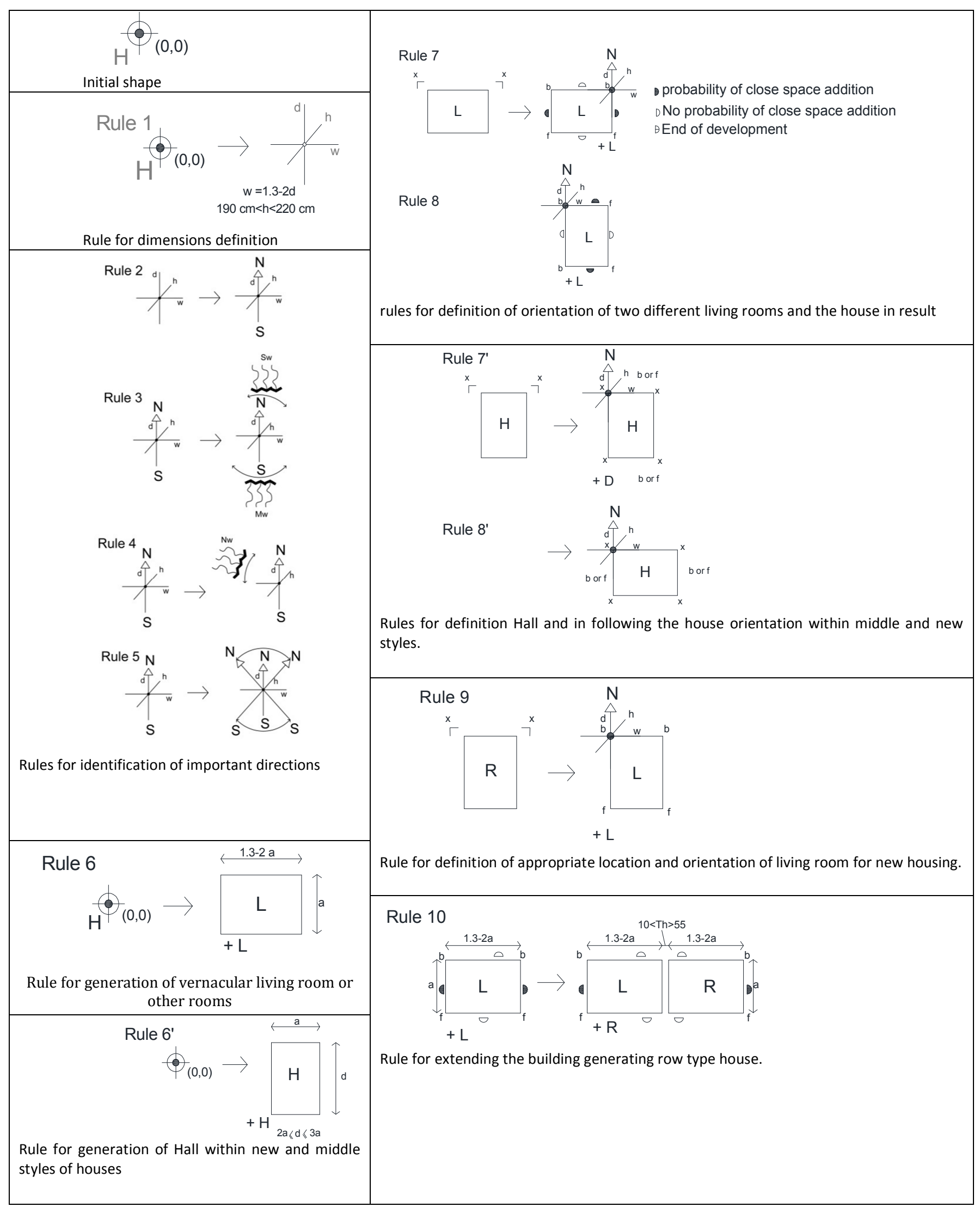




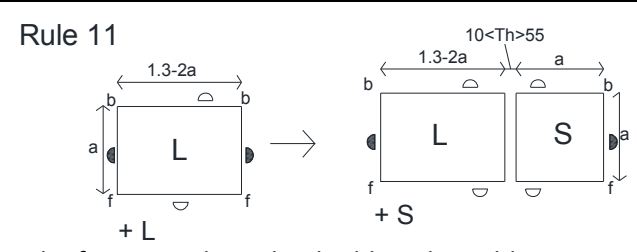

Rule for extending the building by adding a store and generating another row type house.

Rule 12
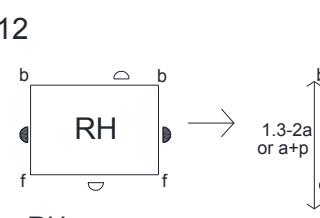

$$
+\mathrm{RH}
$$

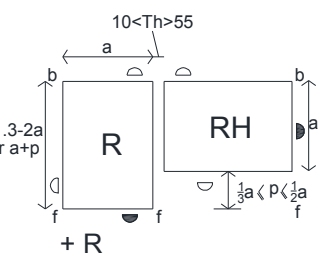

(2)Rule 12

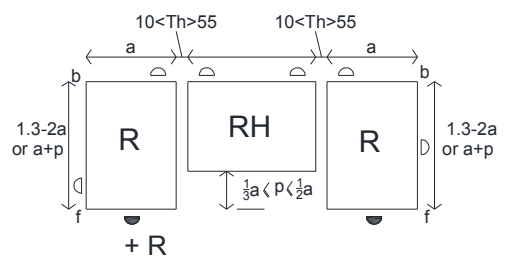

Rule for generation saddle (SH) and half-saddle (HSH) types of house through extension of row type house $(\mathrm{RH})$ or just living room. Therefor the label $(\mathrm{L})$ can be replaced by label $(\mathrm{RH})$ which in this case generates two rooms' half-saddle house and three rooms' saddle type.

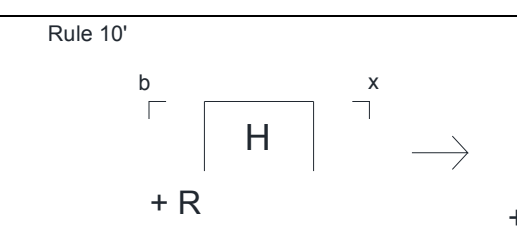

Rule 10"
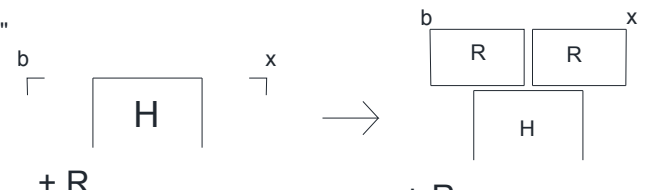

$+\mathrm{R}$

$$
+R \quad x=\text { for } b
$$

Rule 10"'
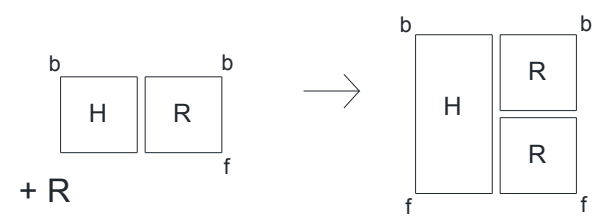

Rule for adding new rooms to central hall in middle and new style of houses.

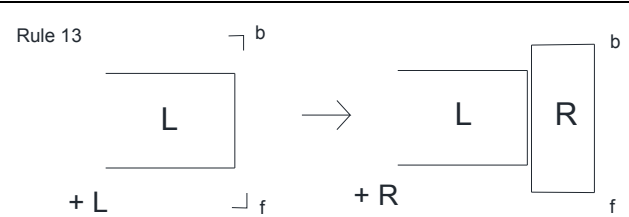

Rule for extending the building from lateral sides of the living room with one big room.

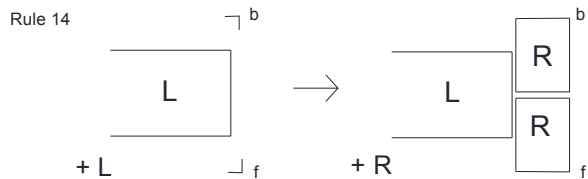

Figure

Rule for extending the building from lateral sides of the living room with two rooms.

Rule 15

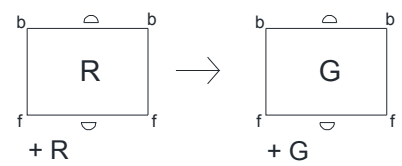

Rule changes the label of the room to generate guest entertainment room.

Rule 16

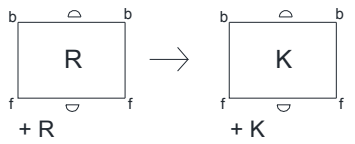

Rule changes the label of the room to generate kitchen.

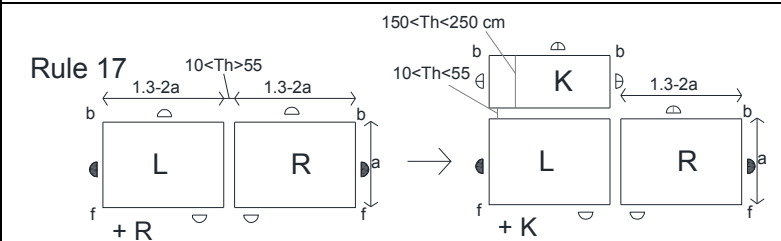

Rule for extension a peripheral room as kitchen at the back of the living room.

Rule 18

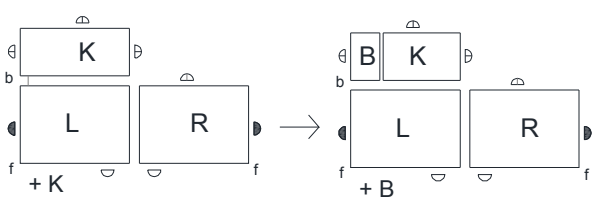

for definition of a space as bath within peripheral kitchen located at the back

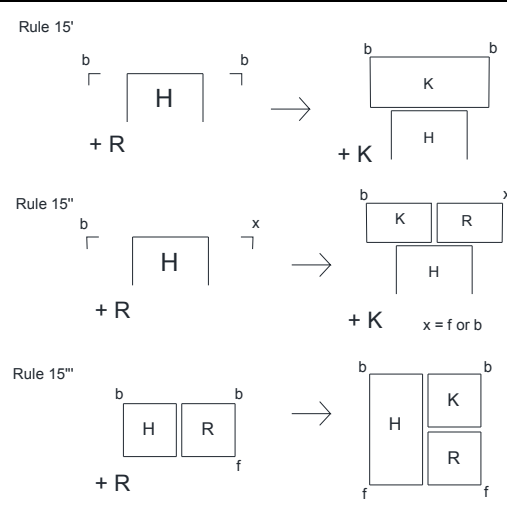

Rule to allocate kitchen within middle and new style house. 


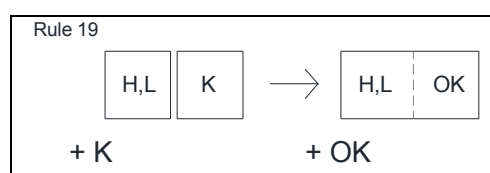

Rule for definition of open plan kitchen.

Rule 20

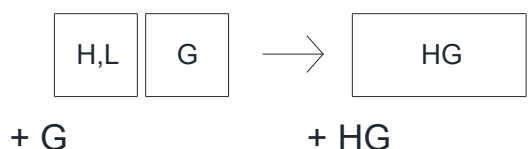

Rule to unify hall and living room with guest entertainment room.

Rule 21

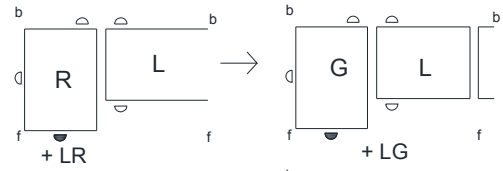

Rule 22

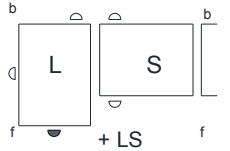

Rule 23

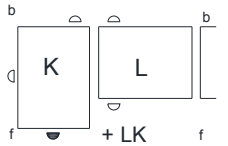

Rule 24

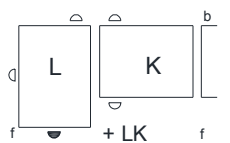

Rules for changing the label of the rooms for changing their function.

Rule 25
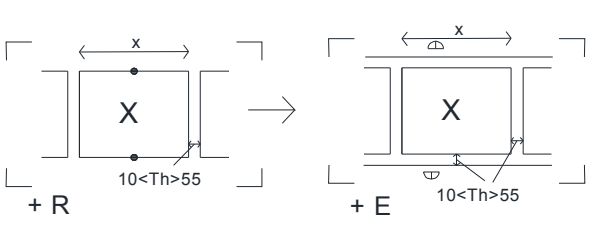

Rule for definition of exterior wall.

Figure

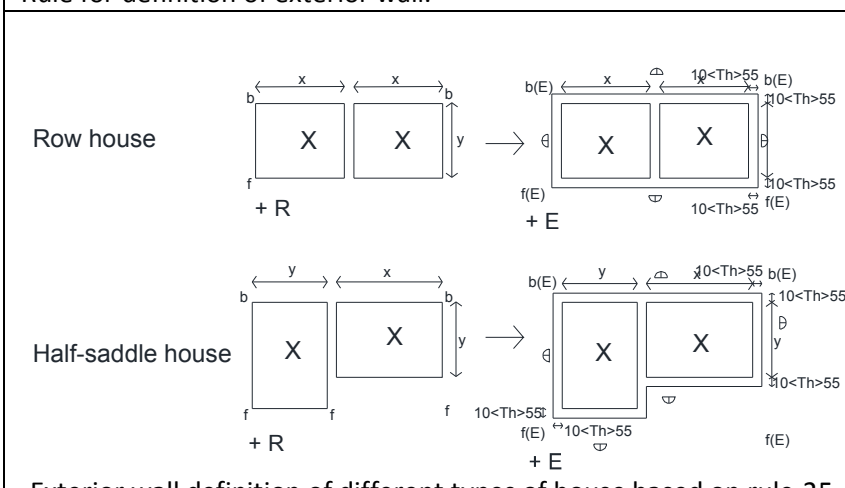

Exterior wall definition of different types of house based on rule-25 application.

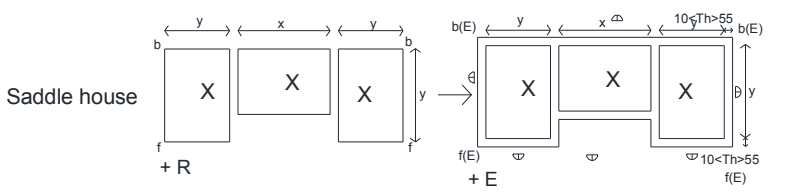

Exterior wall definition of different types of house based on rule25 application.

a End of development

¿No probability of close space addition

- probability of close space addition

- front porch addition

Rule 26
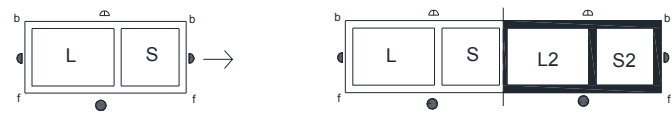

Rule 27

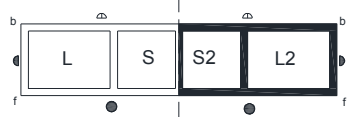

Rule 28

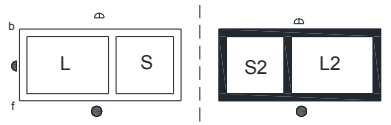

Rule 29

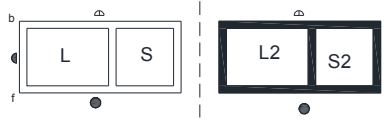

Rule 30
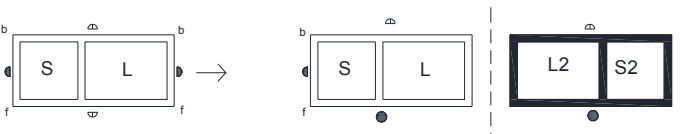

Rule 31

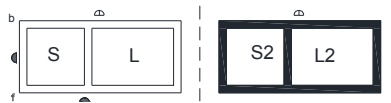

Rule 34'

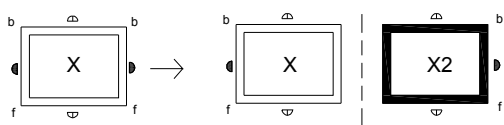

Rule 34"

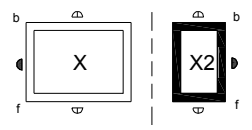

Rule 34"'

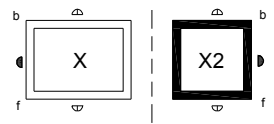

Rule 34"'

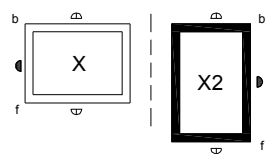

Rules to generate variations of Composite type from combination of Row types with two rooms from rule 26 to rule 31 and one room with another room making Row and Half-Saddle types by application of rules $34^{\prime}$ to $34^{\prime \prime \prime \prime}$. 


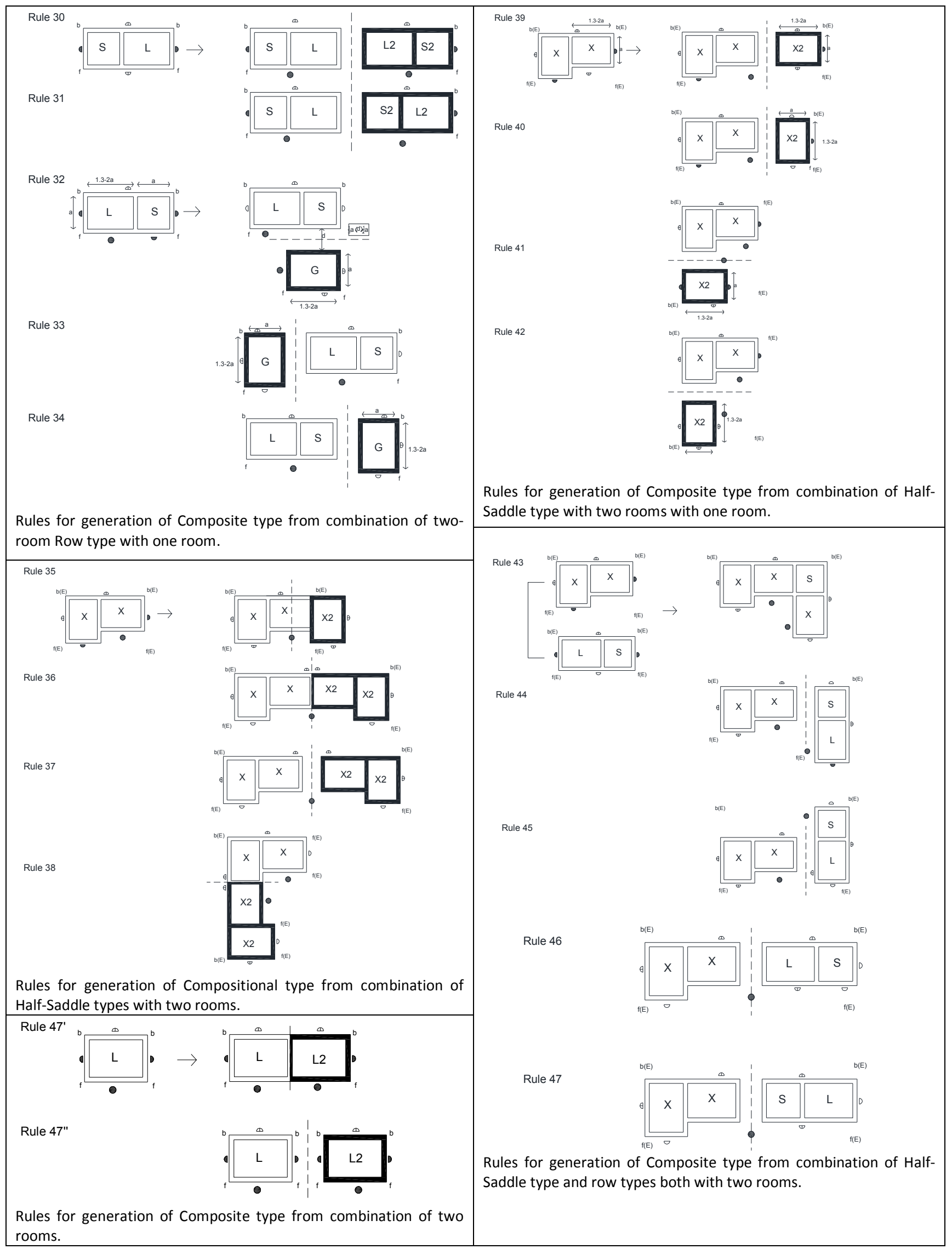


Rule for changing the characteristic and function of corridor within compositional rule to be adapted for new lifestyle. This space could be occupied as a store, which can be accessed from the living room or as a stairs case allowing access to upper floors as a result of rules 47 '"s (fig 10.42) and 47'"'st (fig 10.43) respectively.

Rule $47^{\prime \prime} \mathrm{s}$
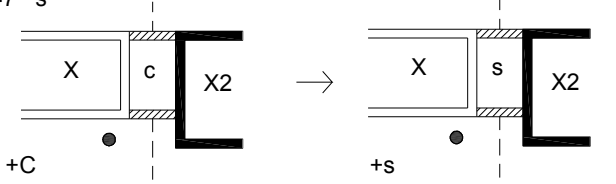

Rule to use the corridor as store room Rule 47"'st
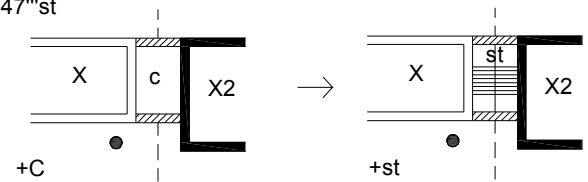

Rule to define the corridor as stairs case

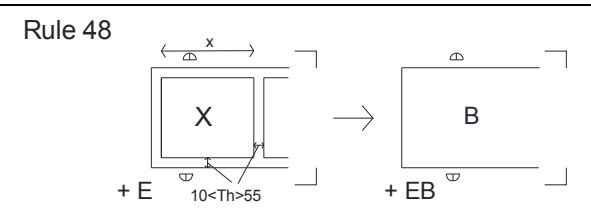

Rule for definition of exterior boundary of house.

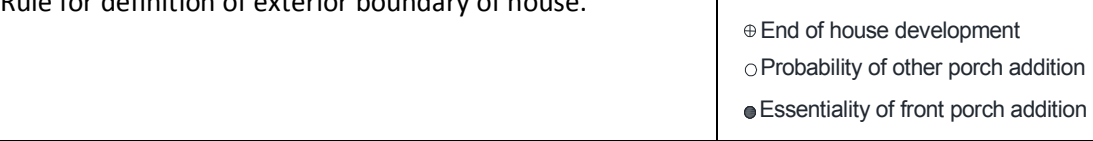

Rule 50
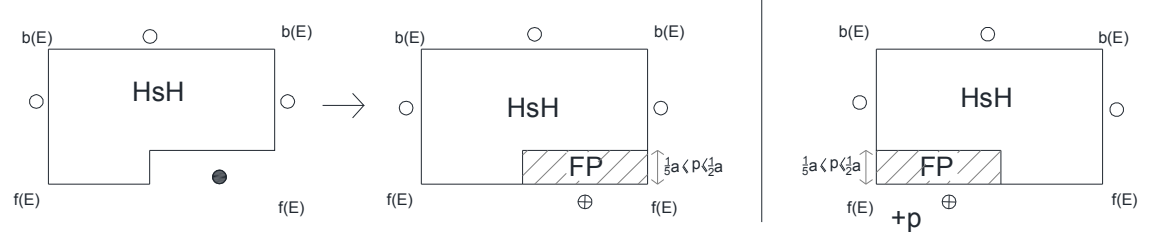

Rule 51
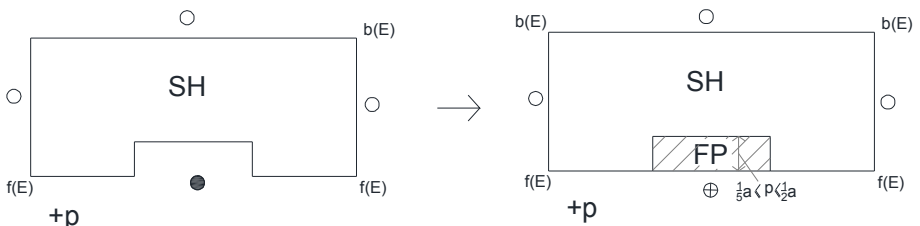

Rules for definition of front porch within three main vernacular house types. Front porch and all of other porches are climatic space, which promote socialisation (Foruzanmehr, 2015) and make the street safe because residents can keep an eye to the street from this space (Jacobs, 1961). 
Rules for possible definition of other porches in different directions of Row type house.

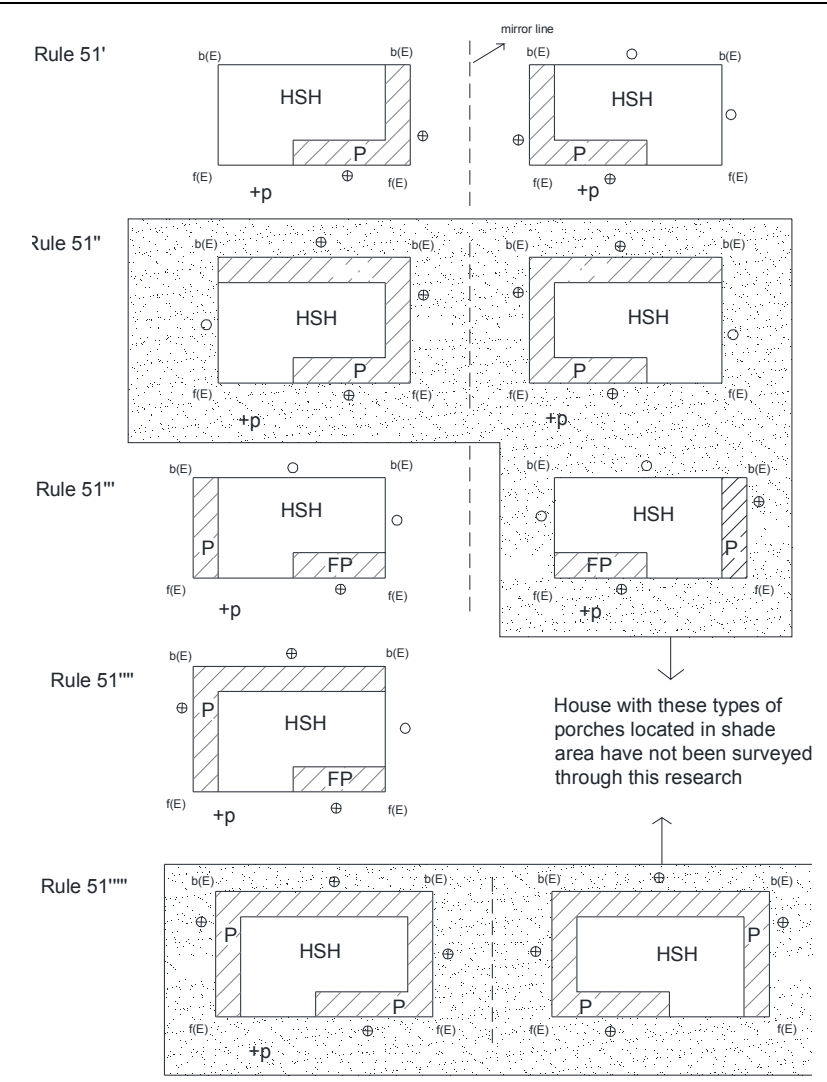

Rules for possible definition of other porches in different directions of Halfsaddle type.

Rule 50'

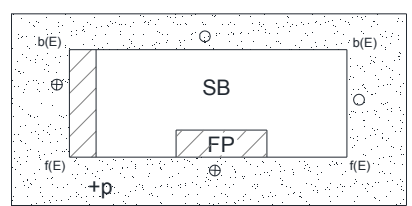

Rule 50"

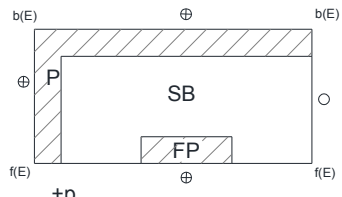

Rule 50"'

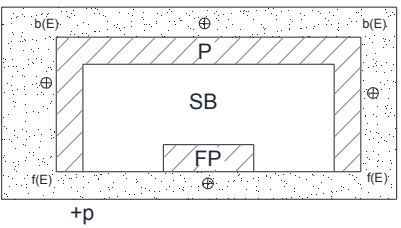

$f(E)$

$\mathrm{CP}$

$\mathrm{RH}$ area have not been surveyed through this research

$b(E)$

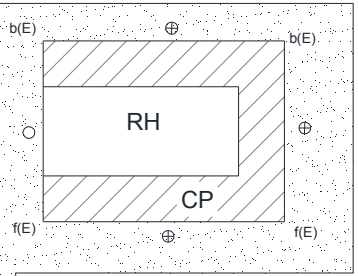

House with these types of
Figure

Rules for possible definition of other porches in different directions of Saddle type.
Rule 49n

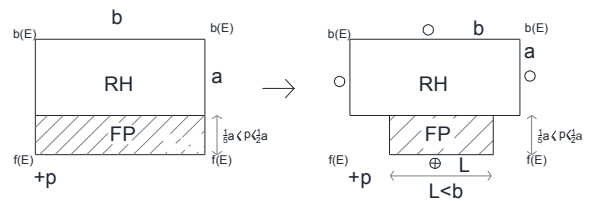

Rule for shortening the size of the front porch in new rural house to reduce the expense of construction.

Rule 52

$$
\text { out } \prod_{n}^{x} \text { in } \prod^{x} \text { out } \rightarrow \text { out in }
$$

Rule for definition of small balconies on first floor.

Rule 53

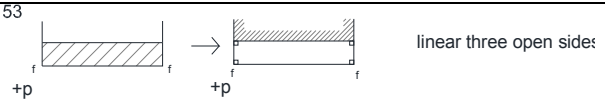

Rule 54

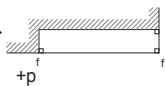

linear two open sides

Rule 55

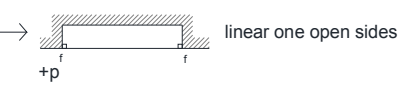

Rule 56

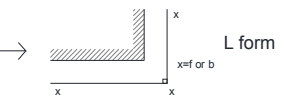

Rules to define wooden columns at the corners of semienclosed space. 
Rule 57
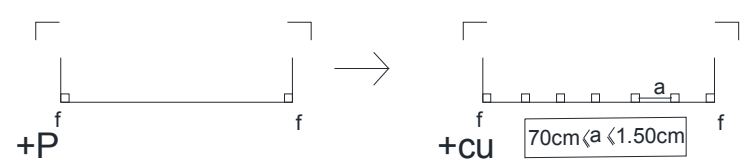

Rule for definition of row of columns in semi-enclosed spaces between columns located at the corners.

Rule 58

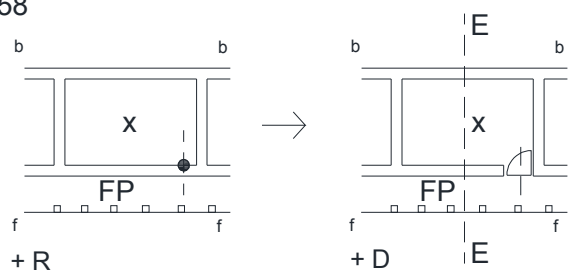

Rule for adding a door to a room.
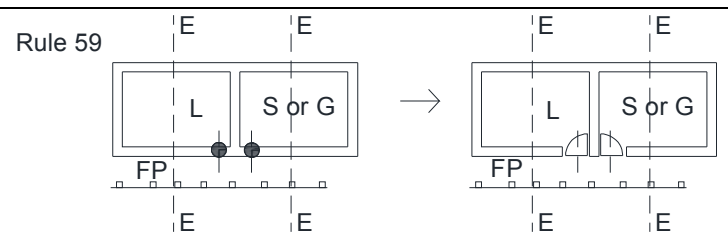

Rule 60
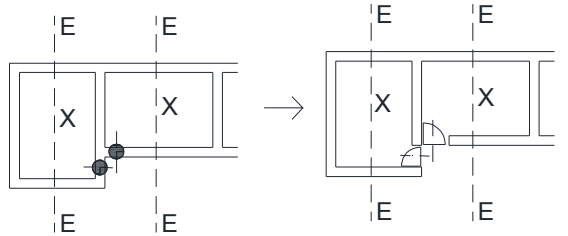

Rule for definition of the location of doors of the adjacent rooms

Rule 61
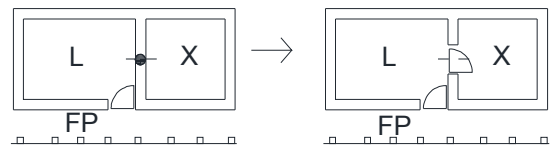

$\mathrm{X}=$ Store room,Kitchen,

Guest entertaining room,

or even bedroom in

new houses

Rule for definition of internal doors connecting two rooms from inside of the living room.

Rule 62

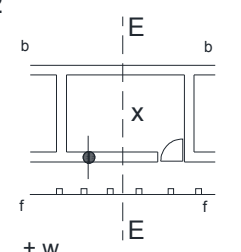

$$
+\mathrm{w}
$$

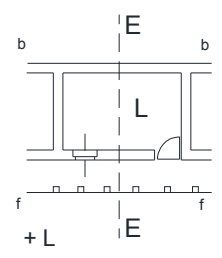

Rule for definition of front window.
Rule 63

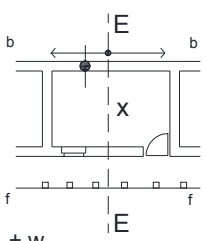

$+\mathrm{w}$

iE

Rule for definition of backward window.

Rule 64
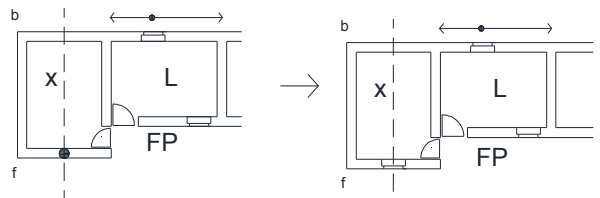

Rule for definition of front side window in lateral room of Half-Saddle and Saddle types.

Rule 65
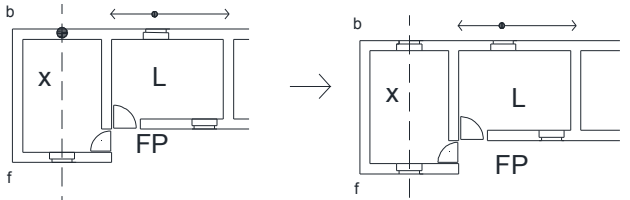

Rule for definition of backside window in lateral room of Half-Saddle and Saddle types.

Rule 66
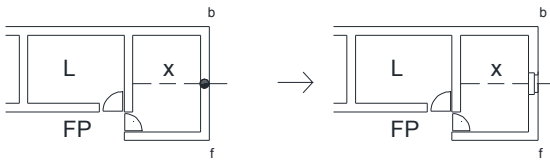

Rule 67
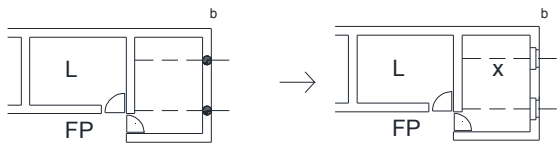

Rule for definition of windows on lateral wall of the house.

Rule 68

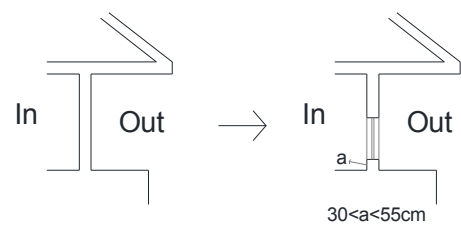

Rule for definition of window O.K.B.

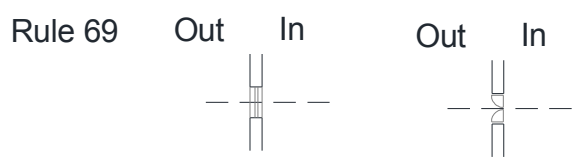

Rule for definition of door-window opening. 


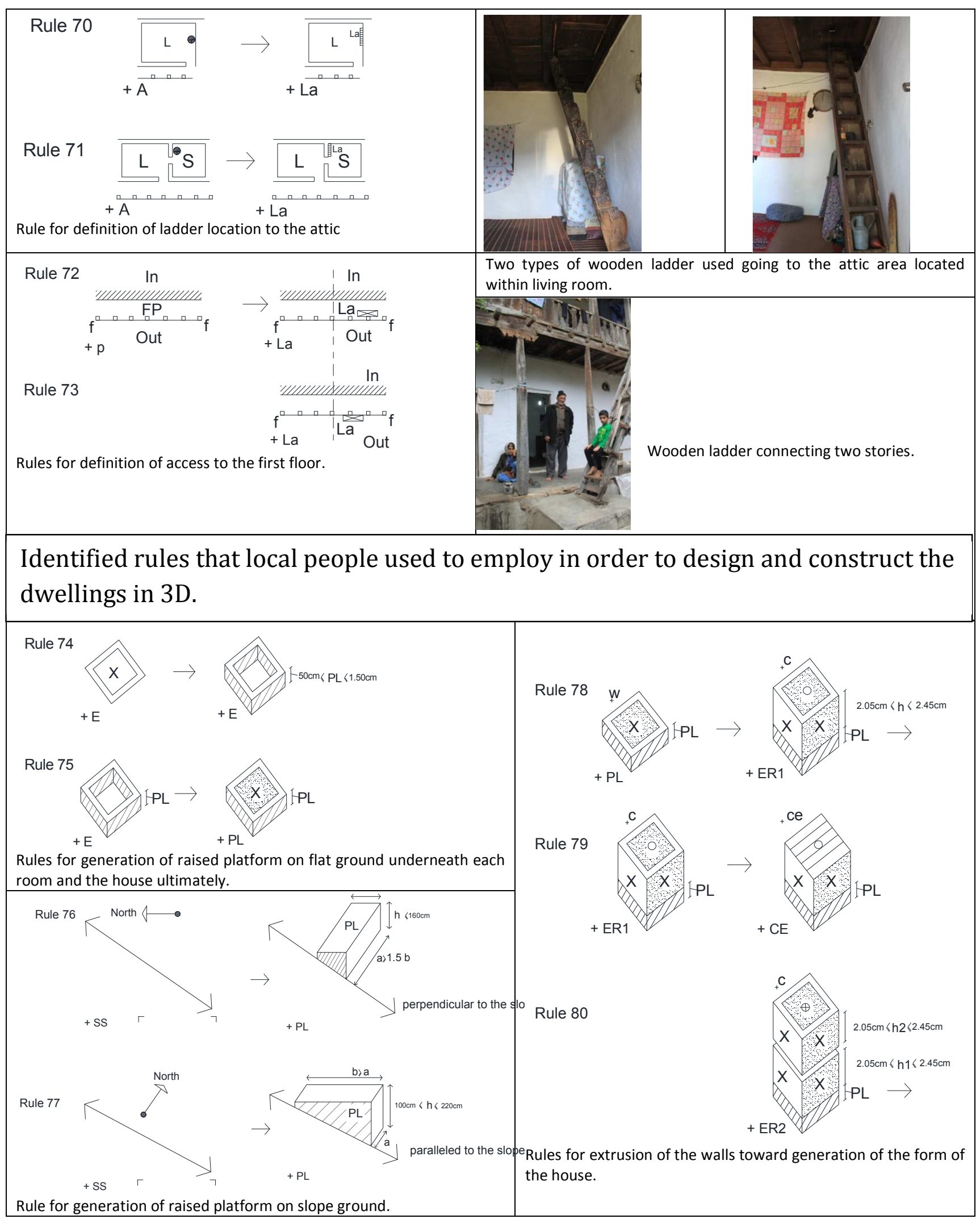




\section{Page 25 of 26}

1
2
3
4
5
6
7
8
9
10
11
12
13
14
15
16
17
18
19
20
21
22
23
24
25
26
27
28
29
30
31
32
33
34
35
36
37
38
39
40
41
42
43
44
45
46
47
48
49
50
51
52
53
54
55
56
57
58
59
60

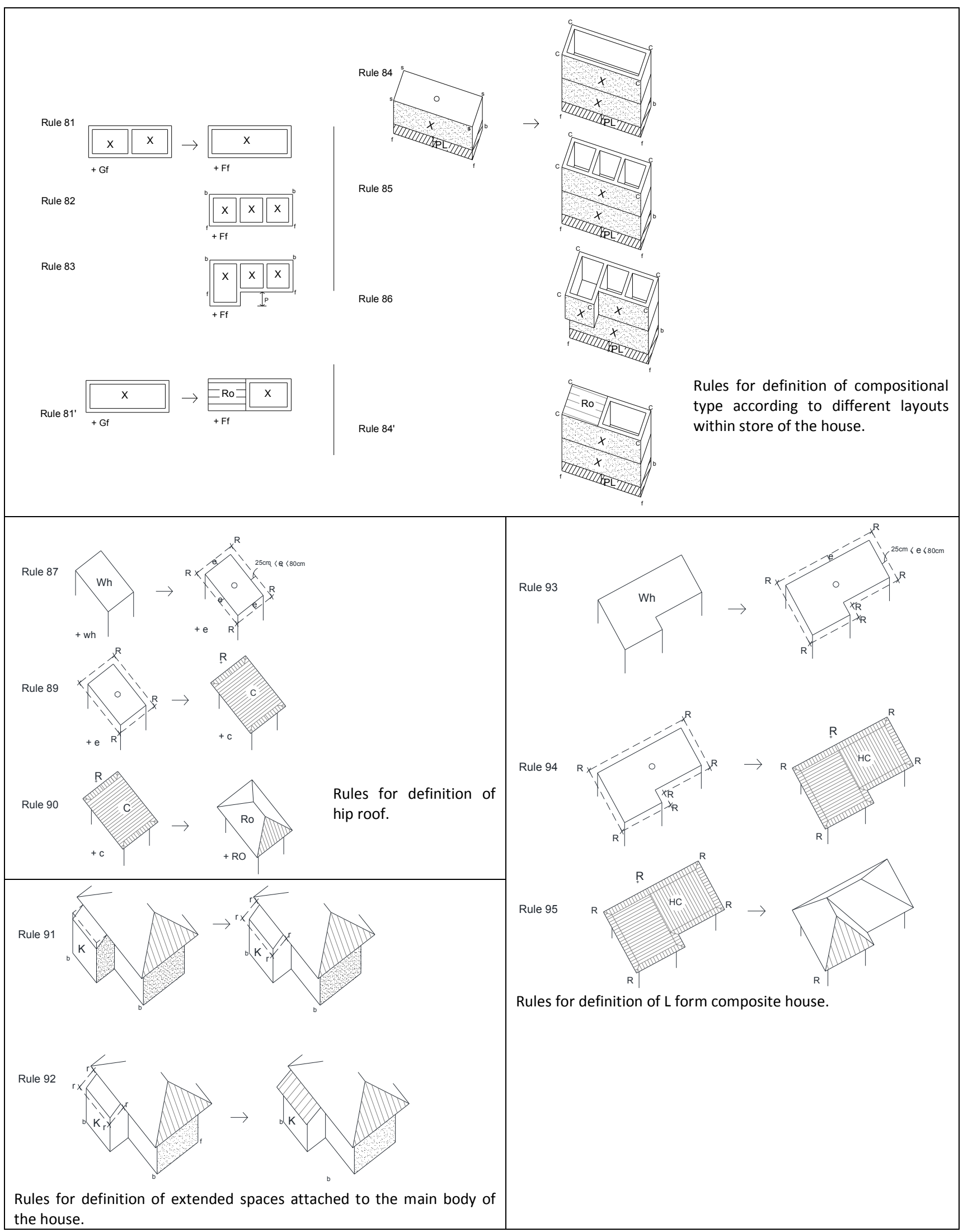




\section{Identified rules in order to define the location of outbuildings, bath, toilet and}

kitchen.

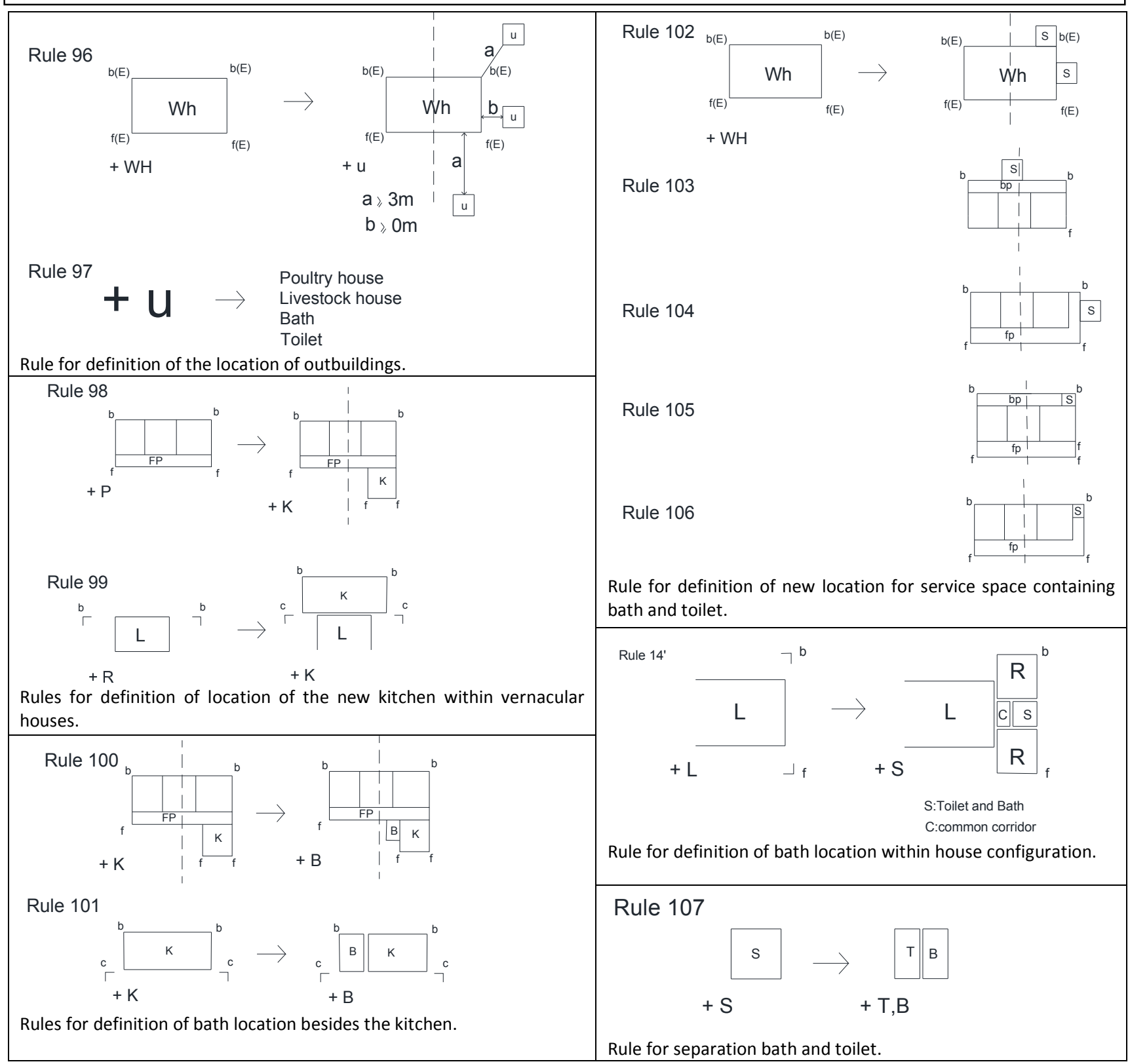

